\title{
Erratum: Triad3A, an E3 ubiquitin-protein ligase regulating Toll-like receptors
}

Tsung-Hsien Chuang \& Richard J Ulevitch Nature Immunology 5, 495-502 (2004).

In Figure 3b, the conditions above the blot were mislabeled and in Figure 6e, HKSA and OspA were mislabeled. They are labeled correctly here. Nature Immunology regrets these errors.

Fig. 3b

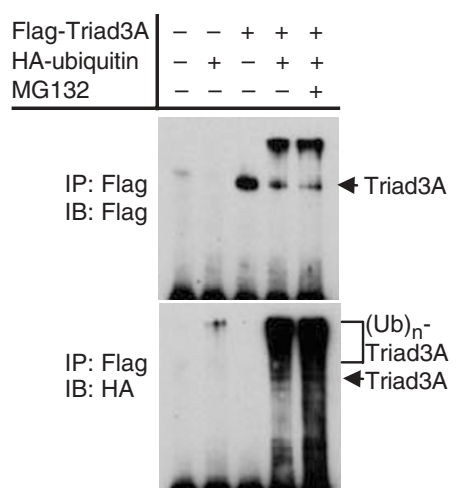

Fig. $6 e$

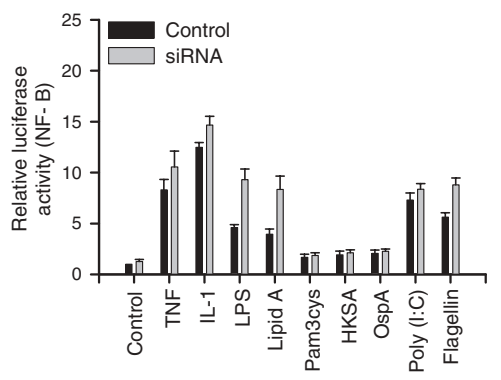

